Prospective Assessment

\title{
Policies and Events Affecting Prescription Opioid Use for Non-Cancer Pain Among an Insured Patient Population
}

Brian K. Ahmedani, PhD ${ }^{1}$, Edward L. Peterson, $\mathrm{PhD}^{2}$, Karen E. Wells, MPH${ }^{2}$, David E. Lanfear, MD, MS ${ }^{1,3}$, and L. Keoki Williams, MD, MPH'1,3

From: ${ }^{1}$ Center for Health Policy and Health Services Research, Henry Ford Health System, Detroit, MI; '2Department of Public Health Sciences, Henry Ford Health System, Detroit, MI; ${ }^{3}$ Department of Internal Medicine, Henry Ford Health System, Detroit, MI

Address Correspondence: Brian K. Ahmedani, PhD Center for Health Policy and

Health Services Research Henry Ford Health System 1 Ford Place, $3 \mathrm{~A}$

Detroit, Michigan 48202 E-mail: bahmedal@hfhs.org

Disclaimer: The authors were supported by grants from the Fund for Henry Ford Hospital

(B.K.A., L.K.W., and D.E.L.) and the National Institutes of Health (L.K.W.: Ro1DK64695 and RorAlo79139).Conflict of interest: Each author certifies that he or she, or a member of his or her immediate family, has no commercial association (i.e., consultancies, stock ownership, equity interest, patent/licensing arrangements, etc.) that might

pose a conflict of interest in connection with the submitted manuscript.

Manuscript received: 11-12-2013 Revised manuscript received: 01-08-2014

Accepted for publication: 01-22-2014

Free full manuscript: www.painphysicianjournal.com
Background: Rising prescription opioid use and abuse have prompted widespread concern. However, to date there have been few rigorous investigations into the policies and events which may have contributed to these trends.

Objective: This study investigates trends in opioid use and related adverse events among individuals with non-cancer pain before and after implementation of major national policies.

Study Design: The study used a longitudinal prospective study design. The analysis was limited to adults (age $\geq 18$ years) without a recorded cancer diagnosis. Pharmacy claims were used to assess rates of prescription opioid use, the strength of opioids dispensed, the proportion using opioids chronically, and related adverse events. Time trend analysis was used to identify changes in these rates over time. The study was Institutional Review Board approved.

Setting: Study patients were members of a large, health maintenance organization in southeast Michigan, with longitudinal records of prescription opioid use.

Results: The analysis comprised 523,623 individuals and 1,066,700 opioid pharmacy fills from January 1, 1997, to December 31, 2011. Contemporaneous with the implementation of health organization accreditation criteria requiring assessment and treatment of pain in all patients beginning January 2001, we observed a consistent and unabated increase in the rate of opioid fills and the proportion of chronic use. A parallel increase in the annual rate of adverse events was also observed. Similarly, we observed a continuous rise in the average strength of opioid fills following January 2001 with the exception of a single drop in December 2010, which was attributable to the withdrawal of propoxyphene from the U.S. market.

Limitations: This was an observational study and not a trial. Other long-term opioid-related benefits or harms, including functional status, quality of life, and substance use disorder, were not assessed.

Conclusions: This study provides temporal evidence for a rise in prescription opioid use after implementation of health organization accreditation criteria requiring standardized management of all individuals with pain.

Key words: Opioid analgesics, chronic pain, chronic drug use, prescription drugs, pain management, propoxyphene, Joint Commission, adverse drug events, morphine dose equivalents, opioid epidemic

Pain Physician 2014; 17:205-216 
n 1999, the Board of Commissioners for the Joint Commission on Accreditation of Healthcare Organizations (JCAHO), now the Joint Commission (JC), approved new standards for the screening, assessment, and management of pain in all patients (1). These standards went into effect on January 1, 2001, and extended to all JCAHO-accredited organizations, such as hospitals, health care networks, behavioral health facilities, home health care organizations, and ambulatory care providers. New policies and procedures were required of organizations as part of the accreditation process with the intent of "institutionalizing" pain management (2). For example, the paradigm shift explicitly involved transforming pain management into a patients' right issue with written recognition of such by organizations seeking accreditation (1,3-5). However, these new standards were not without detractors, some of whom argued that extending these policies to chronic non-cancer pain (CNCP) might pressure physicians to prescribe opioids for indications in which there was little evidence to support their long-term use (6).

Over the past decade, the use of opioids has substantially increased (7-10), such that in 2010, these were the third most frequently dispensed class of medications in the United States and represented an estimated $\$ 8.4$ billion in pharmaceutical sales (11). Commensurate with the rise in opioid use, there has been a parallel increase in drug dependence, overdoses, and overdoserelated deaths (12-16). Opioid pain medication currently accounts for nearly three-quarters of all prescription drug overdose deaths (17). To date, there is little information regarding the possible role that national level events, such as implementation of the JCAHO pain management standards, may have had on rising trends in opioid use.

In this study, we used longitudinal data from a large, insured patient population in southeast Michigan to examine the hypothesis that a temporal relationship exists between opioid use and national-level events, including implementation of the JCAHO pain management standards, which may have influenced these trends. In particular, we examined long-term trends in opioid prescription fills, quantity dispensed, chronic use, and adverse events.

\section{Methods}

\section{Study Population, Setting, and Data Sources}

The study protocol was approved by the Institu- tional Review Board at the Henry Ford Health System. Study patients were members of a large, health maintenance organization (HMO), which provides primary and specialty health care services to residents of southeast Michigan, including the Detroit metropolitan statistical area. Individuals were included in the sample if they were $\geq 18$ years old, had prescription drug coverage, and had no prior or concurrent cancer diagnosis. By virtue of their affiliation with the HMO, study patients had routinely collected electronic records for prescription fills. This included fill information from pharmacies both within and outside of the system and was available for the entire observation period, January 1, 1997, through December 31, 2011.

We used National Drug Code (NDC) numbers to identify opioid pharmacy fills during the observation period both within and outside of the health system using a combination of medical record and insurance claims data on pharmacy fills. Although it is possible that study individuals filled prescriptions covered by other insurers (e.g., through separate health insurance provided through a spouse), we have previously shown for other drug classes that this rarely occurs (18). Data were gathered on the total number of individuals enrolled in the health plan and the total number of opioids filled for each month during the observation period. The rate of opioid fills per month was calculated as the total number of each opioid filled per month divided by the total number of eligible plan members in each month.

The dose strength of each opioid filled was converted into morphine dose equivalents (MDE) in accordance with the method described by Von Korff and colleagues (9). Using this conversion strategy, the dose strength of one milligram (mg) of morphine was 1.0, and every other opioid medication was assigned a conversion value (range $0.1-11.0$ ) based on the relative strength of an equivalent $1 \mathrm{mg}$ amount. Therefore, the total strength of each prescription event was calculated as the milligram per unit (e.g., per capsule, patch, teaspoon, or tablet) of opioid multiplied by the conversion factor multiplied by the total quantity dispensed. An average monthly opioid equivalents value was created by summing the MDEs for all fills and dividing by the total number of opioid prescription fills.

We defined chronic opioid use as having a pharmacy fill for an opioid at least 6 out of 7 consecutive months. For each individual, we created a moving window of opioid use starting with the date of the first recorded opioid pharmacy fill (i.e., the index date). In- 
dividuals were deemed chronic users for the months in which they had filled an opioid prescription in 6 out the 7 preceding months. Because monthly fills could occur at any time during the month (e.g., the start or end of the month), we selected the window (i.e., 7 months) to ensure capture of all continuous use lasting at least half a year. This time frame is supported by research demonstrating that $>3$ months consecutive use is considered chronic (19).

Encounter diagnoses from health care visits were used to identify annual opioid-related adverse events between 1997 and 2011. These adverse events included all opioid-related poisonings and overdose-related deaths. These definitions were based on health care encounter codes used and tested elsewhere (20). International Classification of Diseases, 9th revision (ICD-9) codes used to classify opioid poisoning were 965.0, 965.00, 965.02, 965.09, E850.1, E850.2, E950.0, and E980.0. Vital records from the State of Michigan were matched to study patients using Social Security numbers. The ICD-10 codes $X 42, X 62$, and $Y 12$ were used to detect opioid-related deaths (20).

\section{Statistical Analysis}

Monthly rates of opioid prescription fills (January 1, 1997, through December 31, 2011) were calculated as the proportion of all eligible health plan members with such events in each month, and were then stratified by the Controlled Substance Act schedule. The average MDE was also calculated for prescription fills and represented the average monthly opioid equivalents per fill. The average MDE was then stratified by preparation of opioid dispensed and divided by the total number of all opioid prescriptions filled each month to assess the average contribution of each preparation per prescription. The rate of chronic opioid users was estimated as the proportion of chronic users among the total number of individuals receiving an opioid prescription per month. We used linear regression models to estimate changes in the rate of opioid fills, MDE per fill, and chronic use. We explicitly assessed for changes in the rate curves between the following time intervals: January 1, 1997, through December 31, 2000 (i.e., prior to the implementation of the JCAHO accreditation standards for pain management), January 1, 2001, through November 30, 2010 (i.e., following the implementation of JCAHO accreditation standards for pain management), and December 1, 2010, through December 31, 2011 (i.e., following the withdrawal of propoxyphene from the U.S. market). We also calculated the annual rate of opioid- related adverse events per 100,000 health plan members. We used linear regression to estimate change over time. Lastly, we used local weighted polynomial regression (LOESS) to reassess the inflection point(s) in the plot of prescription opioid fills over time (i.e., dates where the rate of prescription fills per month changed). The number of data points used in calculating the local regression plot at each time point could be varied, and we show the effects of using $5 \%, 20 \%$, and $40 \%$ of the data in each local regression analysis. We defined statistical significance as a $P \leq 0.05$ for the differences in time-trend slopes between study periods.

\section{Results}

The analysis comprised a cumulative total of 523,623 adult health plan members and $1,066,700$ opioid fills over a 15-year period from January 1, 1997, to December 31, 2011. Fig. 1 shows trends in the rates of opioid prescription fills among the study population and Fig. 2 stratifies these rates by schedule of opioid analgesic. From 1997 to 2000, the monthly rate of opioid fills remained constant at just over $1.5 \%$ of members. However, following implementation of JCAHO pain management standards in January 2001, the proportion of members receiving an opioid prescription each month increased to 3.5\% by December 2011. This rate of increase was statistically significant for the time period of January 1, 2001, to November 30, 2010 (see Table 1). Fig. 2 demonstrates that the increase in prescriptions after January 2001 was largely the result of increased dispensing of CSA schedule III opioids. Following the withdrawal of propoxyphene from the U.S. market in November 2010, we observed a parallel increase as compared to period 2.

We used MDEs to summarize the total amount of opioids dispensed in each month. The average MDEs per opioid prescription filled was stable in the time period preceding implementation of the JCAHO pain management standards (Fig. 2 and Table 1). However, in the subsequent 10-year period from January 1, 2001, to November 30, 2010, there was a nearly 2.5 fold increase. However in December 2010, there was a dramatic decrease in opioid MDEs per fill. As displayed in Fig. 4, this drop in MDEs represents the withdrawal of propoxyphene from the U.S. market in mid-November 2010.

Fig. 5 shows the change in proportion of chronic opioid users over time. Between January 1, 1997, and December 31, 2000, there was a gradual rise in the proportion of chronic opioid users among those re- 


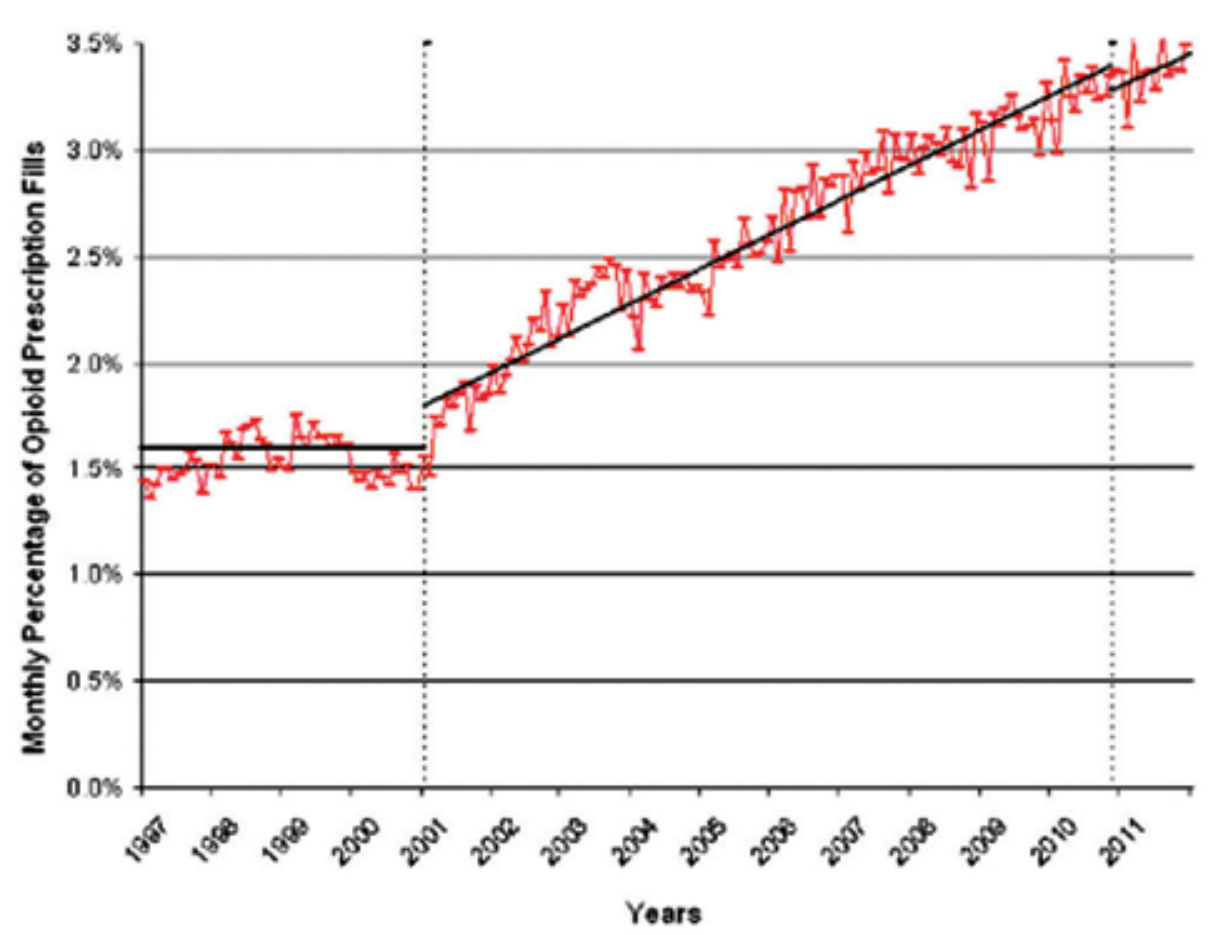

Fig. 1. Trends in the percentage of opioid analgesic prescription fills, $1997-2011$. The red line shows the proportion of health plan members who filled an opioid prescription per month. A solid black regression line shows the trend in each time period.

The vertical dashed line in January 2001 represents when the Joint Commission on Accreditation of Healthcare Organizations pain management standards were implemented. The vertical dashed line in November 2010 represents when propoxyphene was withdrawn from the U.S. market.

Table 1. Comparison of trends in opioid fills, strength, and chronic use before and after implementation of the JCAHO pain management standards and the withdrawal of propoxyphene from the U.S. market.

\begin{tabular}{|l|c|c|c|c|c|c|c|c|c|}
\hline & \multicolumn{2}{|c|}{ Rate of Opioid Pharmacy Fills } & \multicolumn{2}{c|}{ Morphine Dose Equivalents } & \multicolumn{3}{c|}{ Chronic Opioid Use } \\
\cline { 2 - 11 } & Intercept & Slope & $\boldsymbol{P}$-value & Intercept & Slope & $\boldsymbol{P}$-value & Intercept & Slope & $\boldsymbol{P}$-value \\
\hline Period $1^{*}$ & 1.53 & 0.002 & 0.865 & 6.87 & -0.01 & 0.216 & 11.39 & 0.07 & $<0.001$ \\
\hline Period 2 $\dagger$ & 1.29 & 0.012 & $<0.001$ & 1.47 & 0.10 & $<0.001$ & 4.99 & 0.14 & $<0.001$ \\
\hline Period 3 $\neq$ & 1.54 & 0.010 & 0.259 & -3.88 & 0.10 & 0.007 & 17.68 & 0.05 & 0.455 \\
\hline & $\begin{array}{c}\text { Coefficient } \\
\text { Change }\end{array}$ & $\mathbf{9 5 \%}$ CI & $\boldsymbol{P}$-value & $\begin{array}{c}\text { Coefficient } \\
\text { Change }\end{array}$ & $\mathbf{9 5 \% ~ C I}$ & $\boldsymbol{P}$-value & $\begin{array}{c}\text { Coefficient } \\
\text { Change }\end{array}$ & 95\% CI & $\boldsymbol{P}$-value \\
\hline §Slope 2 vs. 1 & 0.01 & $0.01,0.02$ & $<0.001$ & 0.10 & $0.09,0.12$ & $<0.001$ & 0.07 & $0.04,0.09$ & $<0.001$ \\
\hline §Slope 3 vs. 2 & -0.002 & $-0.02,0.02$ & 0.831 & 0.001 & $-0.10,0.10$ & 0.978 & -0.08 & $-0.24,0.07$ & 0.296 \\
\hline
\end{tabular}

JCAHO denotes the Joint Commission for the Accreditation of Healthcare Organizations, and CI, confidence interval.

${ }^{*}$ Period 1 represents January 1997 through December 2000 - the time before implementation of the JCAHO pain management standards in January 2001.

$\dagger$ Period 2 represents the time after implementation of the JCAHO pain management standards in January 2001 through the withdrawal of propoxyphene from the U.S. market in November 2010.

$\$$ Period 3 represents December 2010 through December 2011 - the time after the withdrawal of propoxyphene from the U.S. market.

$\S$ Slopes are calculated using monthly time periods. 


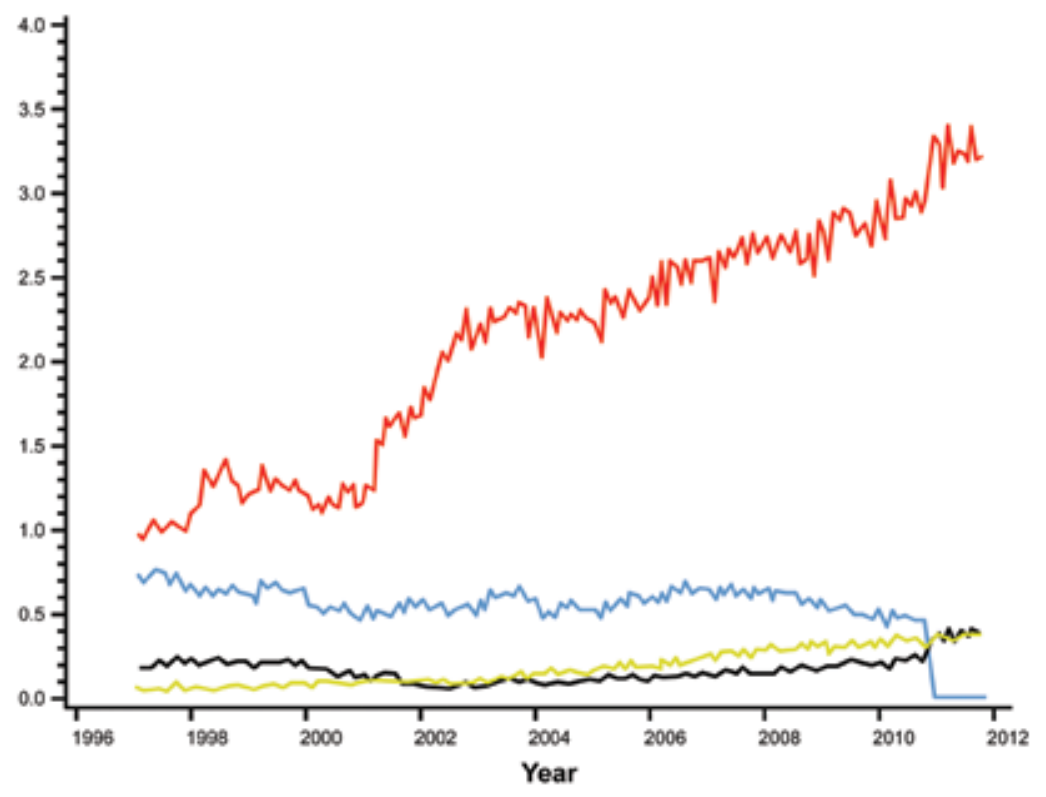

Schedule NA Schedule II Schedule III S Schedule IV

Fig. 2. Trends in the percentage of opioid analgesic prescription fills by schedule of opioid analgesic, $1997-2011$. The red line shows the proportion of health plan members who filled a schedule III opioid prescription per month. The same trend is shown for schedule II (yellow line), schedule IV (blue line, propoxyphene fills only), and non-scheduled (black line, tramadol fills only) opioid prescriptions each month.

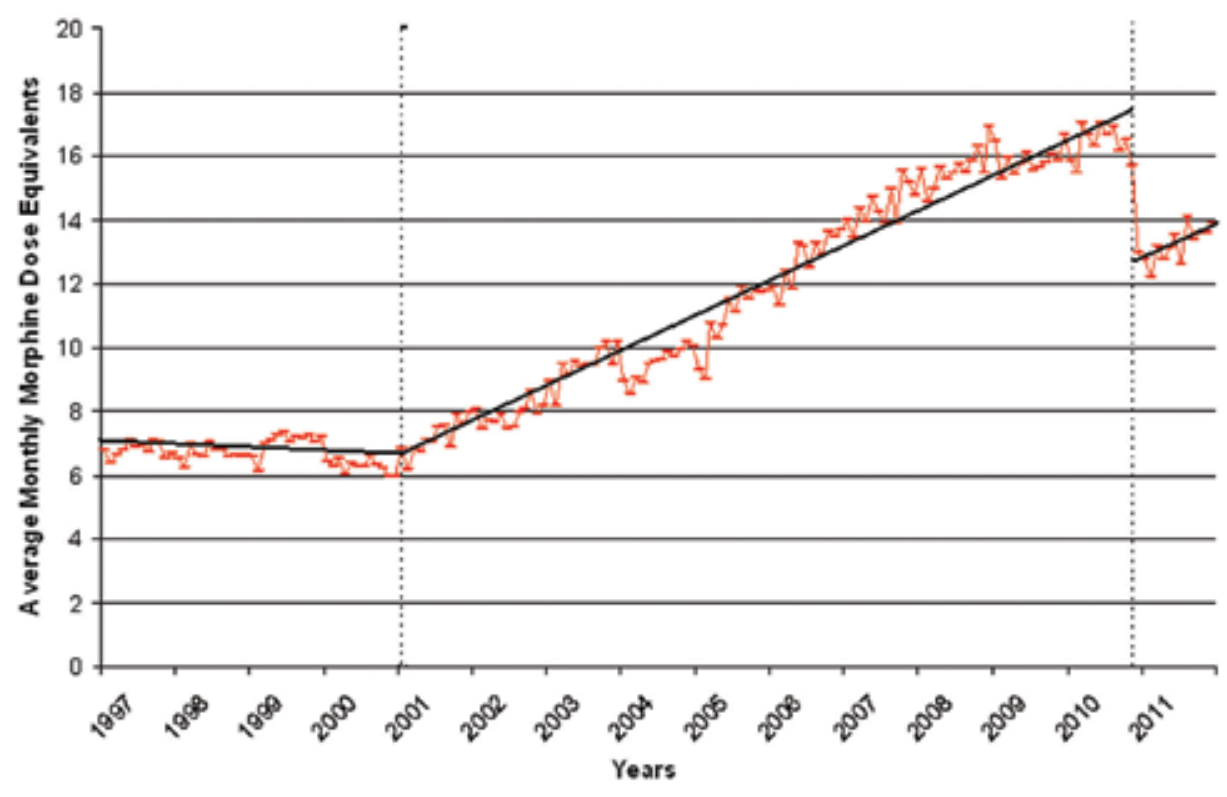

Fig. 3. Trends in average monthly morphine dose equivalents for opioid analgesic prescription fills, $1997-2001$. The red line shows the average monthly strength of all opioid prescriptions filled by health plan members as measured by morphine dose equivalents. A solid black regression line shows the trend in each time period. The vertical dashed line in January 2001 represents when the Joint Commission on Accreditation of Healthcare Organizations pain management standards were implemented. The vertical dashed line in November 2010 represents when propoxyphene was withdrawn from the U.S. market. 


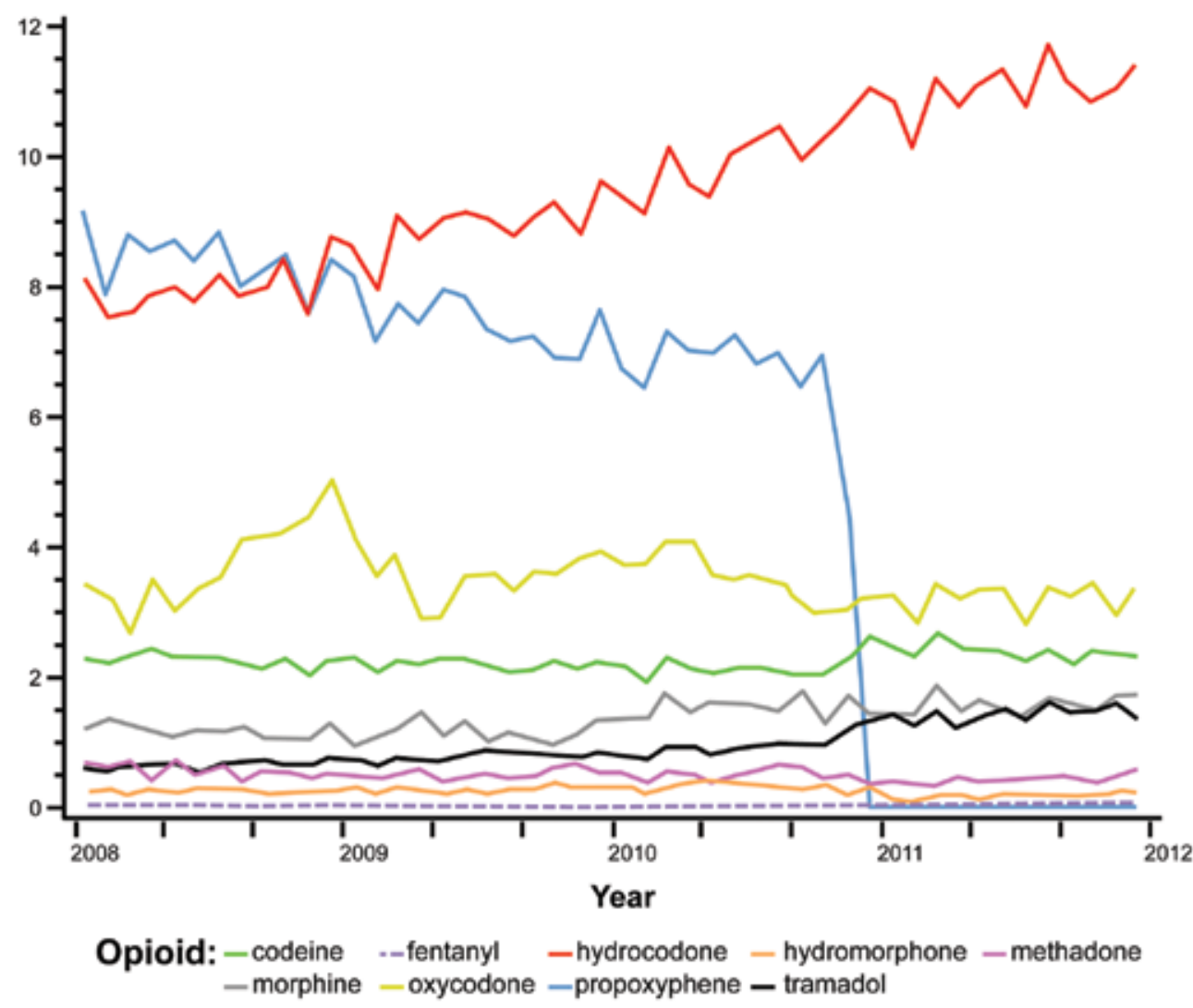

Fig. 4. Trends in average monthly morphine dose equivalents by preparation of opioid analgesic, 2008 - 2011. This figure shows the average monthly strength in morphine dose equivalents of each opioid preparation out of the total number of opioid prescriptions filled among health plan members from 2008 through 2011. In other words, this chart shows the combined contribution of both preparation strength and frequency of use. Commonly prescribed opioids, such as propoxyphene (blue) and hydrocodone (red), comprise a larger share of the monthly morphine dose equivalents when all opioid prescription fills shown are considered. The reduction in propoxyphene shown here corresponds to the time of the reduction in the overall average monthly morphine dose equivalents per prescription in November 2010 , as shown in Fig. 3.

ceiving an opioid fill $(0.07 \%$ increase per month, $P<$ 0.001 ). However for the time period of January 1, 2001 through November 30, 2010, there was a 2-fold increase in chronic opioid users $(0.14 \%$ per month, $P<0.001)$, which was significantly greater than the preceding time period. Following the withdrawal of propoxyphene from the U.S. market, the rise in chronic opioid users flattened for the time period encompassing December 1, 2010, to December 31, 2011 (0.05\% per month, $P=$ 0.455).

Figure 6 shows the annual rate of opioid-related adverse events per 100,000 members. In total, there were 364 adverse events during the observation period, the majority of which were non-fatal poisonings ( $n=315$ versus $n=49$ fatal overdoses). The an- nual rate remained at or below 0.2 per 100,000 health plan members from 1997 through 2001. There was a dramatic 8-fold increase in the rate between 2001 and 2007. The rate then held constant between 1.5 and 1.8 per 100,000 members from 2007 through 2011. The increase in rates observed between 2001 and 2010 (i.e., Period 2) was significant (Slope: $0.170,95 \%$ Confidence Interval: $0.084-0.256, P=0.002$ ).

In post-hoc analysis, the analyses for pharmacy fills, MDEs, and chronic use were repeated after removing tramadol, which does not have a federal CSA designation (although is considered a controlled substance in some states). There was not a significant change in the rates of pharmacy fills or chronic use, or for average MDE in these analyses. Lastly, we used LOESS regres- 


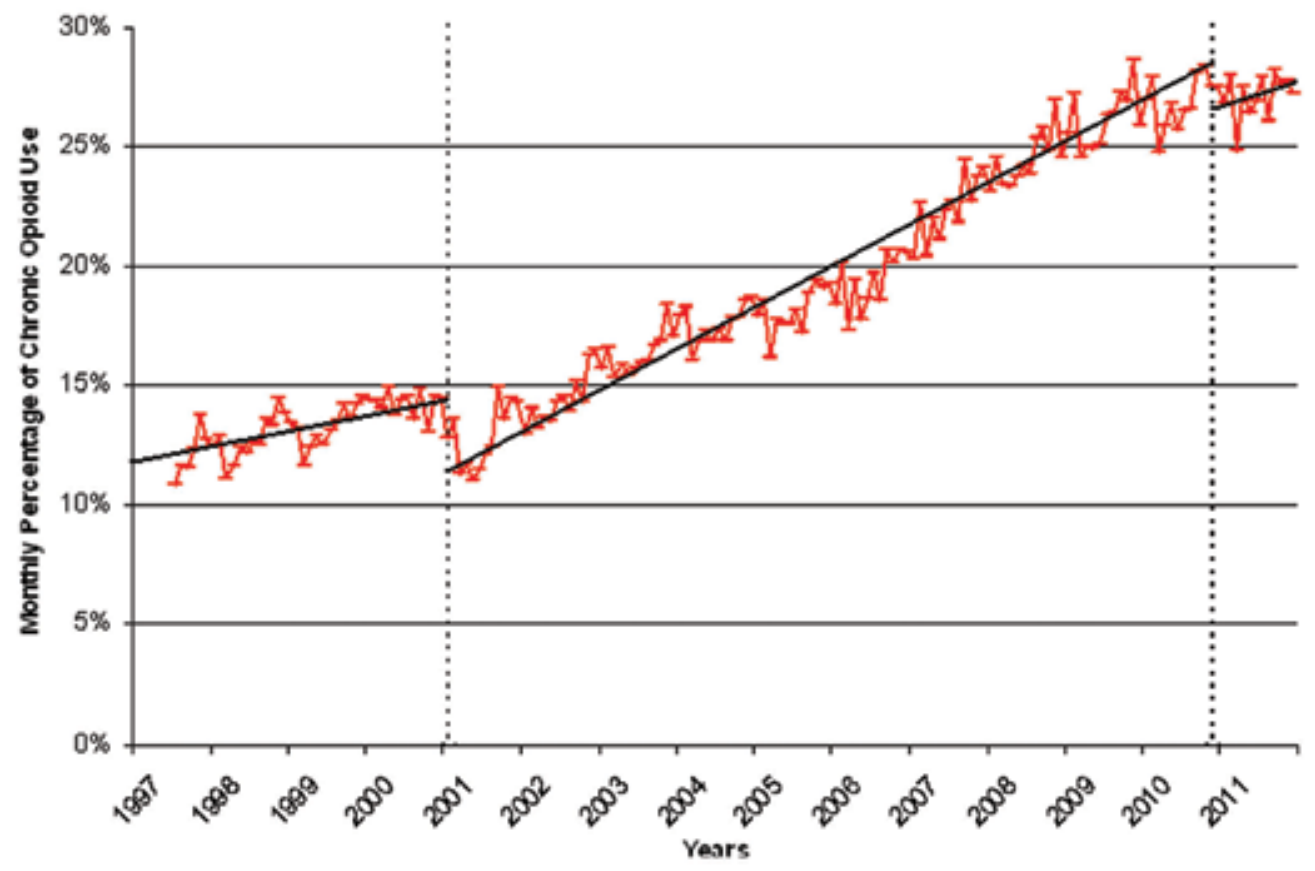

Fig. 5. Trend in the percentage of chronic opioid use, 1997 - 2011. Chronic use was defined as filling a prescription for an opioid in 6 of the 7 preceding months. The red line represents the proportion of chronic opioid users among health plan members receiving an opioid prescription in each month. The solid black regression line represents the time trend in chronic opioid use. The vertical dashed lines represent the implementation of the Joint Commission on Accreditation of Healthcare Organizations pain management standards in January 2001 and the withdrawal of propoxyphene from the U.S. market in November 2010.

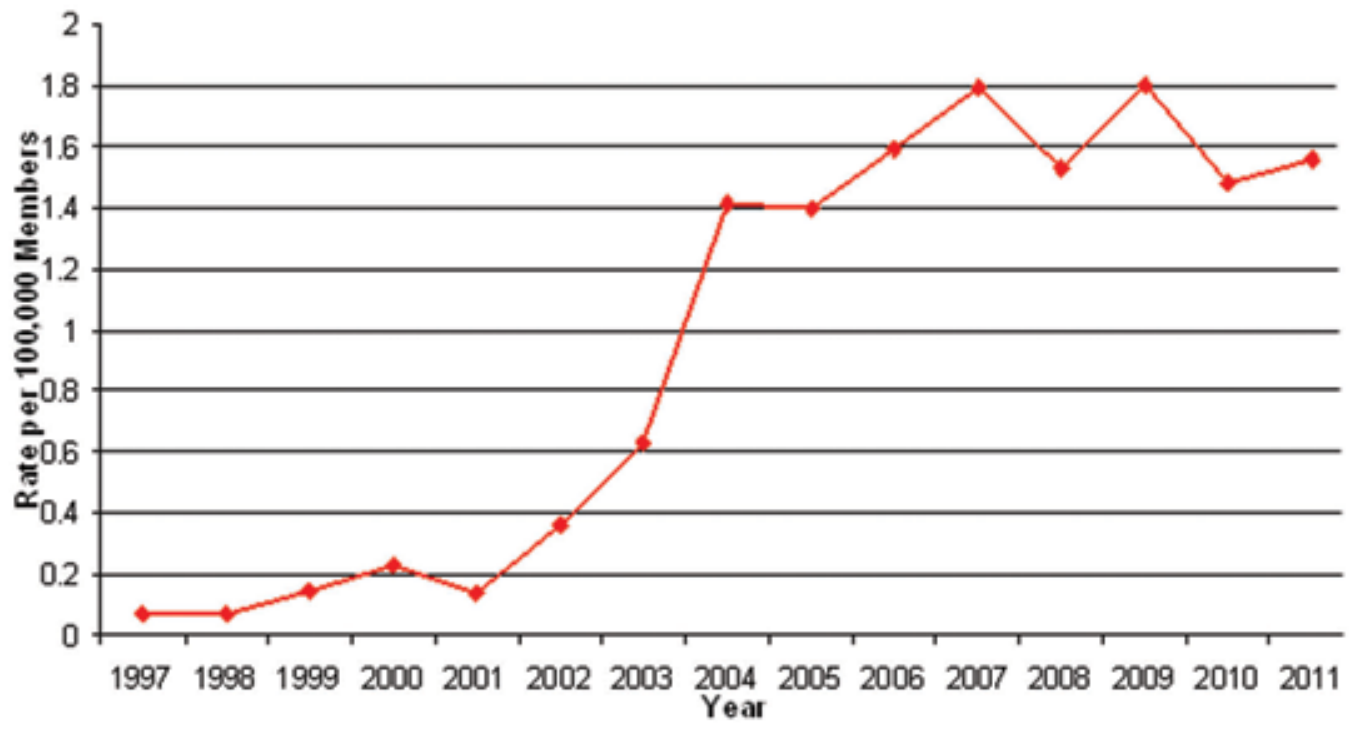

Fig. 6. Annual rate of opioid-related adverse events among health plan members, 1997 - 2011. Opioid-related adverse events are defined as all opioid-related poisonings and overdoses. The red line shows the annual rate of all opioid-related adverse events per 100,000 health plan members. 
sion as an additional method to assess for changes in the rate of prescription opioid fills over time (Fig. 7). Regardless of the smoothing parameter selected (i.e., $5 \%, 20 \%$, and $40 \%$ ), all plots indicated a clear increase in the rate of prescription opioid fills between Decem-

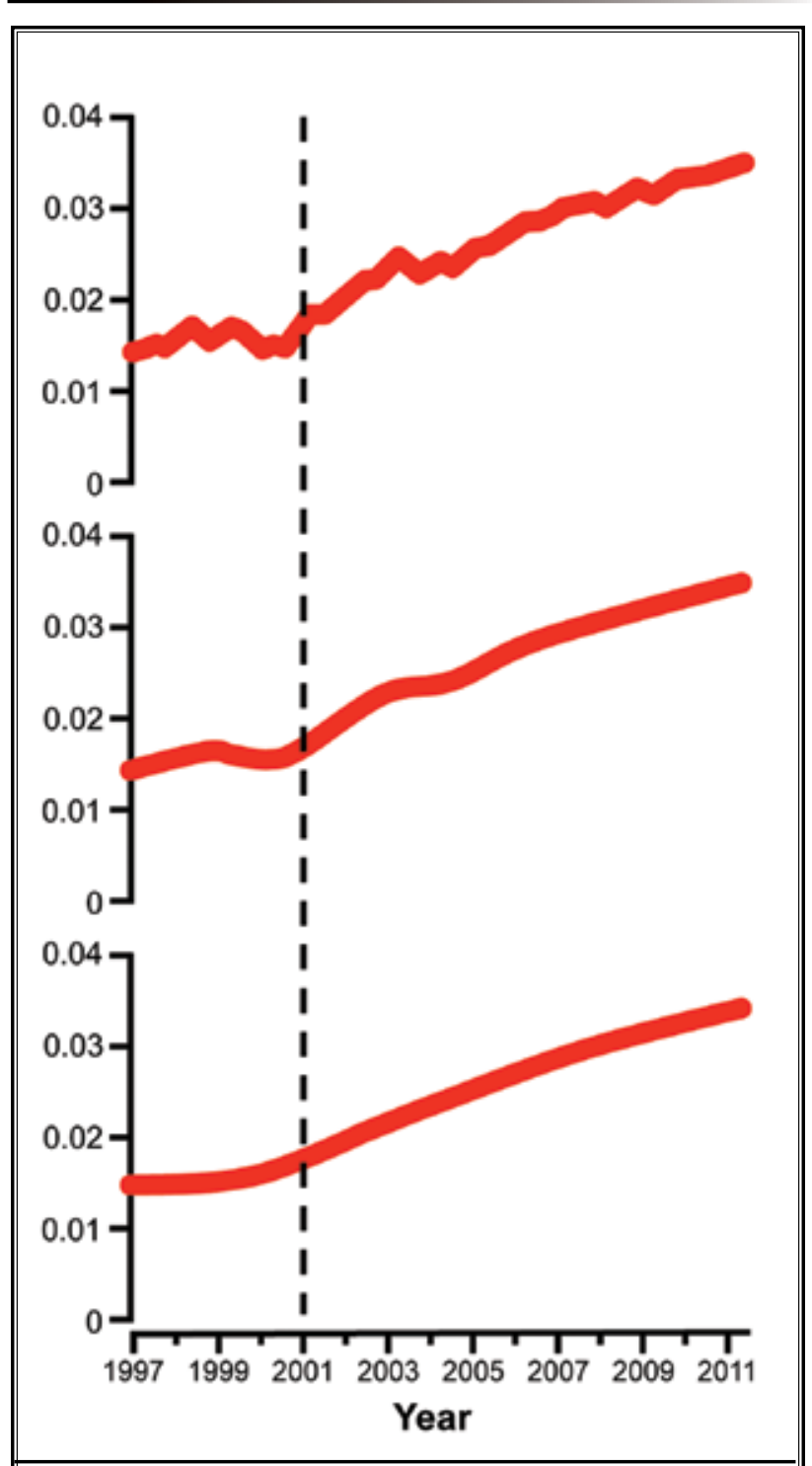

Fig. 7. Trends in the percentage of opioid analgesic prescription fills, 1997 - 2011. Shown is the proportion of health plan members who filled an opioid prescription per month using LOESS regression curves. The LOESS smoothing parameter was varied according the number of data points used in plotting each local regression curve: $5 \%$ (A), $20 \%$ (B), and $40 \%(C)$. The vertical black line is drawn at January 1, 2001, to demonstrate the point at which the JCAHO pain management standards were initiated. ber 2000 and January 2001 (i.e., contemporaneous with the implementation of the JCAHO pain management standards).

\section{Discussion}

In his book titled, A World of Hurt (21), New York Times reporter Barry Meier states that the opioid epidemic "ranks among medicine's biggest mistakes." This epidemic may have been due in part to a series of national events that liberalized the availability and use of prescription opioid analgesics, particularly in the treatment of $\operatorname{CNCP}(12,22)$. However, the impact of specific policies on opioid use has not been well studied until now.

The current study provides a comprehensive investigation of opioid use among members of a large health plan following 2 national-level changes affecting the treatment of pain in the U.S. Our data show a greater than 2-fold increase in the rate of opioid pharmacy fills, quantity of opioid prescribed, and proportion of chronic opioid users following implementation of the JCAHO pain management standards in 2001 and continuing through 2010. It wasn't until the sudden removal of propoxyphene from the U.S. market in November 2010 that we observed some slowing or reversal of these trends. However, the preponderance of evidence within our study population suggests that this downturn will be short-lived as the amount of opioids being prescribed is again increasing as providers prescribe other, stronger opioids in lieu of propoxyphene.

Between 1989 and 1994, the Robert Wood Johnson Foundation (RWJF) funded the Study to Understand Prognoses and Preferences for Outcomes and Risk of Treatments (SUPPORT) (23). The goal of this 2-phase study was to improve end-of-life care for critically ill patients through improved patient-physician communication and decision-making in the areas of patient prognosis, patient preferences, and symptom management. In phase I, interviews with the families suggested that $50 \%$ of conscious patients experienced moderate to severe pain at least half of the time in the last 3 days of life. In phase II of the study, physician practice groups randomized to the intervention group were assigned a skilled nurse to facilitate patient-physician discussions and treatment regarding end-of-life care. Unfortunately, the intervention failed to demonstrate improvement in any of the 5 main outcomes, including pain.

The failure of the SUPPORT trial to improve pain control in severely ill hospitalized patients was the pretext for the RWJF funding a number of initiatives 
around palliative care, including efforts to incorporate pain management into the accreditation process of the JCAHO (24). However, rather than restrict the scope to end-of-life care, in May 1999, the JC approved standards mandating screening for pain among all patients, including those seen in ambulatory care, followed by regular assessment and management at each visit for those who screen positive (1). Similar to a campaign initiated by the Veterans Affairs Administration in 1999, the JC standards were tantamount to treating pain as a "5th vital sign," such that pain was to be measured and addressed at every patient encounter regardless of the initiating complaint (25).

In 1965, the legislature creating Medicare also gave JCAHO statutory authority to accredit hospitals; therefore, at most U.S. health care organizations, Medicare payments became conditional on receiving JC accreditation (26). Although this provision was eventually amended in 2008 (27), around the time that the pain standards were implemented in January 2001, approximately $80 \%$ of U.S. hospitals (comprising $>90 \%$ of all U.S. hospital beds) were JCAHO accredited $(28,29)$. Therefore, organizations providing the vast majority of health care in the U.S. had little option but to comply with the new rules. While the JC disavowed promoting any particular class of medication for pain relief (6), monographs on pain management developed by JCAHO with pharmaceutical industry support included multiple statements promoting the benefits and downplaying the risks of opioids $(30,31)$. A report from the U.S. General Accounting Office in 2003 noted that Purdue Pharma was one of only 2 companies to provide funding for JCAHO's pain educational programs, and they were the only company allowed to distribute certain educational materials pertaining to this training (32).

As this study was conducted among members of a single large health system, it may reflect regional or institution-specific changes in opioid use. Studies in other large health systems, such as Kaiser Permanente Northern California and Group Health in Washington State, have shown patterns of increasing prescription opioid use between 1997 and 2005 (8). Similar to the experience reported here, non-schedule II opioids accounted for the majority of narcotics prescribed, but there were still differences in the types of opioids used between the institutions $(8,9)$. Our findings are also supported by a number of smaller studies whose authors specifically noted an increase in opioid use and complications following institution of the JCAHO pain management standards. These studies include Frasco et al (33), who noted an increase in surgical recovery room opioid use; Tormoehlen et al (34), who described an increase in opioid-related adverse events and deaths involving adolescents reported to the Indiana Poison Center; and Vila et al (35), who observed a more than doubling in the rate of inpatient opioid use over sedation.

Undoubtedly several overlapping efforts at the national and local level may have contributed to the rise in prescription opioid use, particularly for CNCP (36-39). For example, at the national level, a statement was included in the "Victims of Trafficking and Violence Protection Act" designating the decade beginning January 1, 2001, as the "Decade of Pain Control and Research." The designation was emblematic of the monumental changes in attitudes regarding the treatment of pain. These changing attitudes were buoyed by a few small seminal studies $(40,41)$ suggesting that pain was largely undertreated and that the risk of adverse events from chronic opioid use was low. Starting in the 1990s, millions of dollars were spent in advertisement to promote opioids for CNCP, which resulted in billions of dollars in revenue generated (CNCP constituted $86 \%$ of the total opioid market in 1999) (22). In addition, many large organizations and pain experts released statements supporting the use of opioids for all patients during the 1990 s and 2000s $(42,43)$.

Locally, the State of Michigan created a Pain and Symptom Management Advisory Committee in 1998 to provide guidance on policy, public education, and provider education around pain management (44). A legislative report by the committee in June 2001 proposed adopting many of the JCAHO pain management standards, including recognizing pain management as a patient right (45). Most of these recommendations, including the right to pain management, were enacted into Michigan law in 2002 (46).

A number of study limitations must be considered. First, we could not determine whether the patterns of increasing chronic opioid use were associated with better functional status and quality of life, or whether this use was associated with increasing abuse and addiction. Nevertheless, we did document greater opioid-related poisonings, suggesting that the rising trend in opioid use was correlated with some increasing harm. However, since we did not capture cases of substance use disorder, our measures of adverse events likely undercounted the true prevalence of opioid-related harms. In addition, as this is an observational study, we cannot unequivocally link the institution of JCAHO pain stan- 
dards to the rise in prescription opioid use in our patient population. Yet, the consistency of the timing of this rise in prescription opioid use in 2001 suggests that the new JCAHO accreditation standards may have been a precipitating factor. This is supported by our LOESS analysis, which demonstrated a consistent inflection point indicating the beginning of the increase in use in January 2001 when the standards were implemented. Nonetheless, increased use was likely also perpetuated by other national and local events, including subsequent state legislative action.

\section{Conclusions}

Given the absence of evidence supporting the long-term use of opioids in treating $\operatorname{CNCP}(47,48)$ and the rising rates of opioid-related abuse and death $(15,49)$, careful reconsideration must be given to all policies (i.e., both local and national) that may be contributing to this rise. For example, policies establishing pain management as a patient right need to consider assessments by health care providers and the difficult task of discerning chronic pain from drug seeking behavior. Moreover, these policies need to emphasize the importance of investigating and treating root causes of pain, rather than symptomatic management alone.
In addition, high-quality (preferably federally funded) studies are desperately needed to address knowledge gaps regarding the benefits and risks of chronic opioid use for non-cancer pain $(50,51)$. For example, some studies suggest that prolonged opioid use results in hyperalgesia rather than analgesia $(52,53)$; this needs to be studied more thoroughly. More research is needed to understand whether opioids are efficacious for long-term use among individuals with intractable non-cancer pain. Until this information is available, policies supporting such use for pain control should be cautioned.

\section{Acknowledgments}

The authors were supported by grants from the Fund for Henry Ford Hospital (B.K.A., L.K.W., and D.E.L.) and the National Institutes of Health (L.K.W.: R01DK64695 and R01Al079139). The content is solely the responsibility of the authors and does not necessarily represent the official views of the funding agencies. Each author had full access to the data and they take responsibility for the integrity of the data and accuracy of the data analysis. All authors declare no other support for the submitted work. All authors have contributed to and have approved the final submitted manuscript.

\section{References}

1. Berry PH, Dahl JL. The new JCAHO pain standards: Implications for pain management nurses. Pain Manag Nurs 2000; 1:3-12.

2. Berry $\mathrm{PH}$. Getting ready for JCAHO just meeting the standards or really improving pain management. Clin J Oncol Nurs 2001; 5:110-112.

3. Lanser P, Gesell S. Pain management: The fifth vital sign. Healthc Benchmarks 2001; 8:68-70, 62.

4. Cleeland CS, Reyes-Gibby CC, Schall M, Nolan K, Paice J, Rosenberg JM, Tollett $\mathrm{JH}$, Kerns RD. Rapid improvement in pain management: The Veterans Health Administration and the Institute for Healthcare improvement collaborative. Clin J Pain 2003; 19:298-305.

5. Phillips DM. JCAHO pain management standards are unveiled. Joint Commission on Accreditation of Healthcare Organizations. JAMA 2000; 284:428-429.

6. Hansen G. Assessment and management of pain. JAMA 2000; 284:2317-2318.
7. Thielke SM, Simoni-Wastila L, Edlund MJ, DeVries A, Martin BC, Braden JB, Fan MY, Sullivan MD. Age and sex trends in long-term opioid use in two large American health systems between 2000 and 2005. Pain Med 2010; 11:248-256.

8. Boudreau D, Von KM, Rutter CM, Saunders K, Ray GT, Sullivan MD, Campbell $\mathrm{Cl}$, Merrill JO, Silverberg MJ, BantaGreen C, Weisner C. Trends in long-term opioid therapy for chronic non-cancer pain. Pharmacoepidemiol Drug Saf 2009; 18:1166-1175.

9. Von Korff M, Saunders K, Thomas Ray G, Boudreau D, Campbell C, Merrill J, Sullivan MD, Rutter CM, Silverberg MJ, Banta-Green C, Weisner C. De facto long-term opioid therapy for noncancer pain. Clin J Pain 2008; 24:521-527.

10. Pletcher MJ, Kertesz SG, Kohn MA, Gonzales R. Trends in opioid prescribing by race/ethnicity for patients seeking care in US emergency departments. JAMA 2008; 299:70-78.
11. IMS Institute for Healthcare Informatics. The Use of Medicines in the United States: Review of 2010. Parsippany, New Jersey,2011.

12. Okie S. A flood of opioids, a rising tide of deaths. N Engl J Med 2010; 363:1981-1985.

13. Alexander GC, Kruszewski SP, Webster DW. Rethinking opioid prescribing to protect patient safety and public health. JAMA 2012; 308:1865-1866.

14. Juurlink DN, Dhalla IA. Dependence and addiction during chronic opioid therapy. J Med Toxicol 2012; 8:393-399.

15. Centers for Disease Control and Prevention. CDC grand rounds: Prescription drug overdoses - A U.S. epidemic. MMWR Morb Mortal Wkly Rep 2012; 61:10-13.

16. Bohnert AS, Valenstein M, Bair MJ, Ganoczy D, McCarthy JF, Ilgen MA, Blow FC. Association between opioid prescribing patterns and opioid overdoserelated deaths. JAMA 2011; 305:1315-1321. 
17. Centers for Disease Control and Prevention. Vital signs: Overdoses of prescription opioid pain relievers - United States, 1999-2008. MMWR Morb Mortal Wkly Rep 2011; 60:1487-1492.

18. Williams LK, Joseph CL, Peterson EL, Wells K, Wang M, Chowdhry VK, Walsh M, Campbell J, Rand CS, Apter AJ, Lanfear DE, Tunceli K, Pladevall M. Patients with asthma who do not fill their inhaled corticosteroids: A study of primary nonadherence. J Allergy Clin Immunol 2007; 120:1153-1159.

19. Martin BC, Fan MY, Edlund MJ, Devries A, Braden JB, Sullivan MD. Long-term chronic opioid therapy discontinuation rates from the TROUP study. J Gen Intern Med 2011; 26:1450-1457.

20. Dunn KM, Saunders KW, Rutter CM, Banta-Green CJ, Merrill JO, Sullivan MD, Weisner CM, Silverberg MJ, Campbell $\mathrm{Cl}$, Psaty BM, Von Korff M. Opioid prescriptions for chronic pain and overdose: A cohort study. Ann Intern Med 2010; 152:85-92.

21. Meier B. A World of Hurt. The New York Times Company, New York, New York, 2013.

22. Van Zee A. The promotion and marketing of oxycontin: Commercial triumph, public health tragedy. Am J Public Health 2009; 99:221-227.

23. A controlled trial to improve care for seriously ill hospitalized patients. The study to understand prognoses and preferences for outcomes and risks of treatments (SUPPORT). The SUPPORT Principal Investigators. JAMA 1995; 274:1591-1598.

24. Welsfeld V, Miller D, Gibson R, Schroeder SA. Improving care at the end of life: What does it take? Health Aff (Millwood) 2000; 19:277-283.

25. Haugh R. Hospitals and clinicians confront a new imperative: Pain management. Hosp Health Netw 2005; 79:51-56, 52.

26. Social Security Amendments of 1965. http://ssa.gov/OP_Home/ssact/compssa.htm. Accessed January 8, 2014.

27. Medicare Improvements for Patients and Providers Act of 2008. www.gpo. gov/fdsys/pkg/PLAW-11opubl275/pdf/ PLAW-11opubl275.pdf. Accessed January 8, 2014.

28. Sprague L. Hospital oversight in Medicare: Accreditation and deeming authority. NHPF Issue Brief 2005; 802:1-15

29. Brasure M, Stensland J, Wellever A. Quality oversight: Why are rural hospi- tals less likely to be JCAHO accredited? The Journal of Rural Health: Official Journal of the American Rural Health Association and the National Rural Health Care Association 2000; 16:324-336.

30. Pain Assessment and Management: An Organizational Approach. Joint Commission on Accreditation of Healthcare Organizations, Oakbrook Terrace, IL, 2000.

31. Improving the Quality of Pain Management Through Measurement and Action. Joint Commission on Accreditation of Healthcare Organizations, Oakbrook Terrace, IL, 2003.

32. OxyContin Abuse and Diversion and Efforts to Addrss the Problem. US General Accounting Office. Washington, DC,2003.

33. Frasco PE, Sprung J, Trentman TL. The impact of the joint commission for accreditation of healthcare organizations pain initiative on perioperative opiate consumption and recovery room length of stay. Anesthesia and Analgesia 2005; 100:162-168.

34. Tormoehlen LM, Mowry JB, Bodle JD, Rusyniak DE. Increased adolescent opioid use and complications reported to a poison control center following the 2000 JCAHO pain initiative. Clinical Toxicology 2011; 49:492-498.

35. Vila H, Jr, Smith RA, Augustyniak MJ, Nagi PA, Soto RG, Ross TW, Cantor AB, Strickland JM, Miguel RV. The efficacy and safety of pain management before and after implementation of hospitalwide pain management standards: Is patient safety compromised by treatment based solely on numerical pain ratings? Anesthesia and Analgesia 2005; 101:474-48o, table of contents.

36. Joranson DE, Gilson AM, Dahl JL, Haddox JD. Pain management, controlled substances, and state medical board policy: A decade of change. J Pain Symptom Manage 2002; 23:138-147.

37. Pain and Policy Studies Group. Achieving Balance in Federal and State Pain Policy: A Guide to Evaluation. Second Edition. University of Wisconsin Carbone Cancer Center, Madison, WI, 2003.

38. Pain and Policy Studies Group. Achieving Balance in State Pain Policy: A Progress Report Card. University of Wisconsin Carbone Cancer Center. Madison, WI, 2003.

39. Pain and Policy Studies Group. Achieving Balance in State Pain Policy: A Prog- ress Report Card (CY 2012). University of Wisconsin Carbone Cancer Center. Madison, WI, 2003.

40. Portenoy RK, Foley KM. Chronic use of opioid analgesics in non-malignant pain: Report of 38 cases. Pain 1986; 25:171-186.

41. Porter J, Jick H. Addiction rare in patients treated with narcotics. $N$ Engl J Med 1980; 302:123.

42. Quality improvement guidelines for the treatment of acute pain and cancer pain. American Pain Society Quality of Care Committee. JAMA 1995; 274:1874-1880.

43. Department of Veterans Affairs. Pain

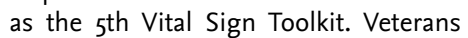
Health Administration, Washington, D.C., 2000.

44. Public Acts of 1998: An Act to Amend Public Health Code Act 368 of 1978. www.legislature.mi.gov/documents/1997-1998/publicact/pdf/1998PA-0332.pdf. Accessed January 8, 2014.

45. State of Michigan, Bureau of Health Services. Pain and Symptom Management Advisory Committee Report. Lansing, Michigan, 2002.

46. Public Acts of 2001: An Act to Ament Public Health Code Act of 1978. 2002. www.legislature.mi.gov/documents/2001-2002/publicact/pdf/2001PA-0236.pdf. Accessed January 8, 2014.

47. Furlan AD, Sandoval JA, Mailis-Gagnon A, Tunks E. Opioids for chronic noncancer pain: A meta-analysis of effectiveness and side effects. CMA] 2006; 174:1589-1594.

48. Noble M, Treadwell JR, Tregear SJ, Coates VH, Wiffen PJ, Akafomo C, Schoelles KM. Long-term opioid management for chronic noncancer pain. Cochrane Database Syst Rev 2010 Jan 20; 1: CDoo6605.

49. Paulozzi LJ, Weisler RH, Patkar AA. A national epidemic of unintentional prescription opioid overdose deaths: How physicians can help control it. J Clin Psychiatry 2011; 72:589-592.

50. Chou R, Ballantyne JC, Fanciullo GJ, Fine PG, Miaskowski C. Research gaps on use of opioids for chronic noncancer pain: Findings from a review of the evidence for an American Pain Society and American Academy of Pain Medicine clinical practice guideline. J Pain 2009; 10:147-159.

51. Chapman CR, Lipschitz DL, Angst MS, Chou R, Denisco RC, Donaldson GW, Fine PG, Foley KM, Gallagher RM, Gilson AM, Haddox JD, Horn SD, Intur- 
risi CE, Jick SS, Lipman AG, Loeser JD, Noble M, Porter L, Rowbotham MC, Schoelles KM, Turk DC, Volinn E, Von Korff MR, Webster LR, Weisner CM Opioid pharmacotherapy for chronic non-cancer pain in the United States: A research guideline for developing an evidence-base. J Pain 2010; 11:807-829.

52. Chu LF, Angst MS, Clark D. Opioid-induced hyperalgesia in humans: Molecu- lar mechanisms and clinical considerations. Clin J Pain 2008; 24:479-496.

53. Chang G, Chen L, Mao J. Opioid tolerance and hyperalgesia. Med Clin North Am 2007; 91:199-211. 